\title{
PHYSIOGNOMY AND NATURAL REGENERATION OF DRY DECIDUOUS FORESTS AT SIGIRIYA, SRI LANKA
}

\author{
G A D Perera \\ University of Peradeniya, \\ Peradeniya.
}

\begin{abstract}
Although, poor natural regeneration of tropical dry forest has been observed in Sri Lanka, India, Africa and in Latin America, the factors affecting this have not been well studied. In this paper, the physiognomy of dry deciduous forests at Sigiriya in the northern dry zone of Sri Lanka and some major factors which affect their natural regeneration were estimated.
\end{abstract}

The vegetation was entumerated in six $20 \times 20 \mathrm{~m}$ experimental plots. The diameter of trees $25 \mathrm{~cm}$ at breast height $(\mathrm{dbh})$ was mcasured. Seed rain was detected by collecting seeds using wooden trays, allowing them to be germinated and cnumerating the germinants over a period of eleven months. The seed bank was examined by collecting ten soil samples from each plot three times within a year. Seedlings were recorded in $2 \times 2 \mathrm{~m}$ quadrates in each plot and their growth and survival was recorded throughout an year. Soil temperature, soil moisture and the canopy openness were also detected.

The species composition and dominant species were identified for dry deciduous forest in the area. The beta diversity of forests is high implying the importance of conserving large areas of dry forests. Scasonality of seed production, seed predation, lack of a persistent seed bank, unfavourable environmental factors are found to be affecting the regeneration of dry deciduous forest. Possibilitics of sustainable timber production in dry deciduous forest and the participation of local people in forest management are also discussed. 